FACULDADE DE CIÊNCIAS ECONÔMICAS DA UFRGS
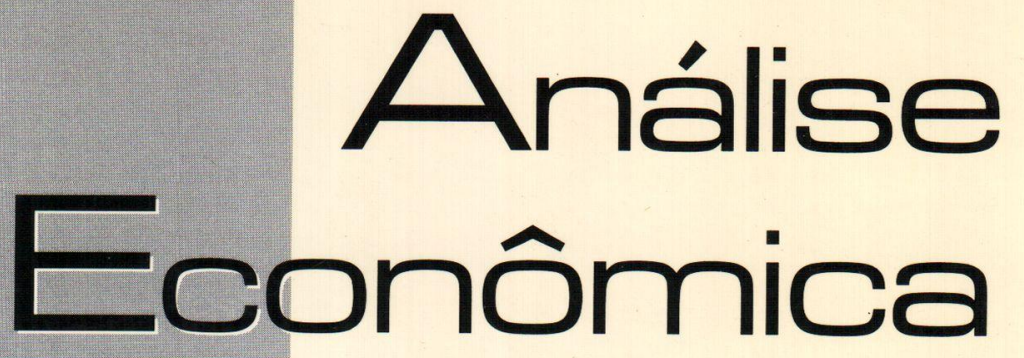

A CIÉNCIA ECONOMICA NA EUROPA E NOS Estados Unidos: PluRAlismo Versus MONISMO

ANTONio Maria da SiLveira

A EXPANSÃO DO COMERCIO MUNDIAL: IMPLICACOO ES SOBRE A HIPÓ TESE DE CONVERGENCIA

MANOEL BOSCO DE ALMEIDA

O SETOR AGRICOLA NA ÁREA DE LIVRE COMERCIO DAS AMÉRICAS: DESAFIOS DA INTEGRAÇÃO REGIONAL

PAULO D. WAQUIL.

PEQUENOS E MEDIOS FABRICANTES DE BENS DE CAPITAL FRENTE AS MUDANÇAS NA ECONOMIA BRASILEIRA

HOYEDO NUNES LINS

RISCOS NA ATIVIDADE BANCÁRIA EM CONTEXTO DE ESTABILIDADE DE PREÇOSE DE ALTA INFLAÇÃO

LUIS FERNANDO RODRIGUES DE Paula

O FIO DA NAVALHA DE HARROd EA RESPOSTA DA ESCOLA DE CAMBRIDGE MARIo AUGusto Bertella

A DINAMMICA FINANCEIRA INTERNACIONAL E A TENDENCIA Ã DOLARIZAÇÄO DAS ECONOMIAS LATINO-AMERICANAS

MARCOS ANTONIO MACEDO CinTRA

TEMPORALIDADE DA RIQUEZA - TEORIA DA DINAMMICA E FINANCEIRIZAÇÃO DO CAPITALISMO - RESENHA

Gentil Corazza

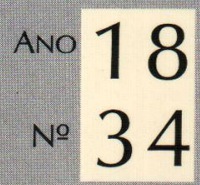


Universtode Federal do Rio Grande do Sul

Reitora: Prof ${ }^{a}$. Wrana Maria Panizzi

Faculdade de Crências Econômicas.

Diretora: Prof ${ }^{4}$. Otilia Beatriz Kroeff Carrion

Centro de Estudos e Pesquisas Econômicas

Diretor: Prof. Fernando Ferrari Filho

Departamento de Ciências Económicas

Chefe: Prof. Luiz Alberto Oliveira Ribeiro de Miranda

Departamento de Crências Contábeis e Atuariais

Chefe: Prof. João Marcos Leão da Rocha

Curso de Pós-Graduação em Economia

Coordenador: Prof Marcelo Savino Portugal

Curso de Pós-Graduação em Desenvolvimento Rurai

Coordenador: Prof Carlos Guilherme A. Mielitz Netto

Consel.ho Eomorial: Achyles B. Costa, Aray M. Feldens, Carlos A Crusius, Carlos G. A Mielitz Netto, Eduardo A. Maldonado Filho, Eduardo P. Ribeiro, Eugênio Lagemann, Fernando Ferrari Filho, Gentil Corazza, Jan A. Kregel, Marcelo S. Portugal, Nali J. Souza, Otília B. K Carrion, Paulo A. Spohr, Paulo D. Waquil, Pedro C. D. Fonseca, Philip Arestis, Roberto C. Moraes, Ronald Otto Hillbrecht, Stefano Florissi, Eleutério F. S. Prado (USP), Fernando H Barbosa (FGV/RJ), Gustavo Franco (PUC/RJ), João R. Sanson (UFSC), Joaquim P. Andrade (UnB), Juan H. Moldau (USP), Paul Davidson (Univ of Tennessee), Werner Baer (Univ. of Mlinois)

Comissāo Eoitonial: Eduardo Augusto Maldonado Filho, Fernando Ferrari Filho, Gentil Corazza, Marcelo Savino Portugal, Paulo Dabdab Waquil, Roberto Camps Moraes.

EdITor: Gentil Corazza

EdrTor Adjunto: Pedro Silveira Bandeira

Secretarus: Márcio Souza de Vargas

REVISĩo de teXtos: Vanete Ricacheski

Fundador: Prof. Antônio Carlos Santos Rosa

Os materiais publicados na revista Análise Econômica são da exclusiva responsabilidade dos autores. É permitida a reprodução total ou parcial dos trabalhos, desde que seja citada a fonte. Aceita-se permuta com revistas congêneres. Aceitam-se, também, livros para divulgação, elaboração de resenhas e recensões. Toda correspondência, material para publicação (vide normas na terceira capa), assinaturas e permutas devem ser dirigidos ao seguinte destinatário:

Prof. Genth Corazza

Revisia Anáxise Econômica - Av. João Pessoa, 52 CEP 90040-000 PORTO ALEGRE - RS, BRASIL

Telefones: (051) 316-3513 316-3440 - Fax: (051) 316-3990 rae@vortex.ufrgs.br

Análise Econômica

Ano $18, n^{\circ} 34$, setembro, 2000 - Porto Alegre

Faculdade de Ciências Econômicas, UFRGS, 2000

Periodicidade semestral, março e setembro

1. Teoria Econômica - Desenvolvimento Regional Economia Agrícola - Pesquisa Teórica e Aplicada -

Periódicos. I Brasil

Faculdade de Ciências Econômicas,

Universidade Federal do Rio Grande do Sul.

CDD 330.05

CDU $33(81)(05)$ 


\section{O Tempo do Capital Financeiro}

Gentil Corazza

O tempo é o devorador das coisas, diz um adágio latino. A verdade dorme no tempo, diz a poesia de Lya Luft, em Histórias do Tempo. Enfim, tudo se passa no tempo ou tudo passa pelo tempo, que a tudo perpassa.

Existe um tempo econômico que transforma permanentemente o sistema e devora os fundamentos de nossa pobre ciência econômica? Decifra-me ou te devoro nos diz o tempo da economia, qual esfinge de pedra indestrutível ao passar do tempo e das intempéries das areias.

A teoria econômica convencional por longo tempo fingiu poder ignorar o tempo da economia, mas depois, para não ser por ele devorada, o reconheceu apenas como tempo lógico ou tempo-espaço, tempo manso coabitando com seu equilíbrio. Kalecki sinalizou para um tempo mecânico, regular e repetitivo. Keynes foi o teórico moderno do tempo econômico, um tempo futuro expectacional cujas "forças obscuras" dominam cálculos, convenções e decisões econômicas e movem permanentemente e sem descanso o sistema. Schumpeter passou do equilíbrio para o tempo da "destruição criadora". Para Marx, o tempo econômico é o tempo do capital, que submete a economia ao "fetiche da mercantilização". O tempo do capital é tempo de trabalho abstrato, o tempo do trabalho socialmente necessário. Capital como categoria e realidade histórica - temporalidade lógico-histórica, gênese/natureza e desenvolvimento das formas capitalistas. Minsky tratou do tempo das finanças capitalistas.

É com base nessas questões, que José Carlos de Souza Braga articula sua visão da teoria crítica para trabalhar a temporalidade da riqueza. Para ele, o tempo é o tempo do capital e o tempo do capital é um tempo financeiro. Temporalidade da Riqueza - teoria da dinâmica e financeirização do capitalismo $o^{2}$ significa que o tempo produz mutações na "definição, gestão, e realização" da riqueza. A forma capitalista de acumular riqueza não é nem natural, nem eterna, mas histórica. A Riqueza das Nações é produto do trabalho, já reconhecia sabiamente Adam Smith. E a riqueza capitalista sofre metamorfoses, passando por muitas formas, desde a forma concreta, mercadoria, até a forma abstrata, dinheiro, o qual também passou por metamorfoses, desde a materialidade dos metais até o dinheiro papel e avança para o dinheiro

\footnotetext{
1 Economista e Professor da UFRGS.

2 Temporalidade da Riqueza - teoria da dinâmica e financeirização do capitalismo. José Carlos de Souza Braga Unicamp/Instituto de Economia, 2000.
} 
cibernético. Esta riqueza dos homens, diz Braga, já se encarnou tipicamente na terra sólida e nas suas edificações, ampliando-se em direção à riqueza de papel (paper wealth), com sua mobilidade, virtualidade, incerteza e intrigante concretitude simbólica.

Mas é preciso não esquecer, acentua, que a riqueza capitalista tem origem no trabalho dos homens, progressivamente minimizado em face do gigantismo da produtividade social que ele mesmo engendrou, ou o tempo de trabalho torna-se uma base miserável para a imensa massa de valor que deve funcionar como capital. Por isso, os movimentos e metamorfoses da riqueza são provocados pela lógica interna do capital, ou seja, o tempo econômico é o tempo do capital e o tempo do capital é o tempo das finanças, que ditam o ritmo da economia.

Desse modo, a compreensão da dinâmica do capitalismo depende de como se compreende o tempo lógico e o tempo histórico e sua relação recíproca. A teoria convencional não consegue "passar o Rubicão". Marx, Schumpeter, Keynes e Kalecki, cada um com seu método, procuram efetivar essa passagem, dando conteúdo lógico-histórico à dinâmica capitalista. $O$ ponto de encontro do pensamento crítico compreende: a crítica à idéia de ciclo como totalidade autônoma de movimento, o resgate da teoria da demanda efetiva de Keynes, Kalecki e Minsky, a afirmação da categoria do capital em geral de Marx, concretizado como capitais centralizados, cuja concorrência estabelece a dinâmica das formas do movimento, instabilidade e crise ao longo do tempo. Finalmente, na dinâmica da riqueza no capitalismo contemporâneo, "valorização e concorrência operam sob a dominância da lógica financeira".

O livro se compõe de duas partes: na primeira, analisam-se as aporias ou os becos sem saída dos modelos da teoria "clássica" e os avanços da teoria crítica. O dilema da teoria econômica sempre residiu em descobrir a passagem da estática para a dinâmica, ou seja, o dilema do Equilíbrio e do Tempo. Os capítulos desta primeira parte abordam, desde a "dinâmica formal" da teoria clássica, (Smith, Ricardo, Walras, Pigou e Marshall), passando por Schumpeter, "que transita do fascínio analítico pelo paradigma do equilíbrio para a teoria da instabilidade estrutural", chegando a Kalecki e Keynes e Marx, num esforço, talvez o mais bem-sucedido, de articulação da teoria da acumulação de capital com a teoria da demanda efetiva.

Na segunda parte, analisa-se a dinâmica financeira do capitalismo contemporâneo. O capítulo 1 destaca como a concorrência das grandes corporações opera em dois processos simultâneos, a geração de renda agregada e a capitalização financeira; o capítulo 2 aborda como a instabilidade estrutural se expressa em flutuações e na "antinomia da tendência". No capítulo final, o autor discute como se move o sistema sob dominância financeira. 
As questões aqui mencionadas indicam por si mesmas a abrangência e relevância da obra do Professor José Carlos Braga para a compreensão do capitalismo de nosso tempo. Nós todos, que tivemos o privilégio de ser seus alunos, e os que conhecem seus trabalhos, sempre tivemos certeza tratar-se de um pensamento abrangente, complexo e reflexivo, uma forma de pensar adequada à natureza complexa do objeto, que procuramos conhecer. Agora, ao lermos Temporalidade da Riqueza, síntese de sua Tese de Doutoramento e de suas últimas pesquisas, podemos afirmar sem receios que o livro do Professor Braga é não apenas relevante, como também indispensável, uma leitura obrigatória para entender o nosso tempo. 